www.jmscr.igmpublication.org

Impact Factor 3.79

Index Copernicus Value: 5.88

ISSN (e)-2347-176x ISSN (p) 2455-0450

crossref DOI: _http://dx.doi.org/10.18535/jmscr/v4i02.79

\author{
Journal Of Medical Science And Clinical Research \\ IGM Publication \\ An official Publication of IGM Publication
}

\title{
The Unexplored Relationship Between Diet \& Mental Health: A Review
}

\author{
Authors \\ Preeti Khanna ${ }^{1}$, Dr Bani T. Aeri \\ ${ }^{1}$ Ph.D Research Scholar, Dept. of Food \& Nutrition, Institute of Home Economics, Delhi University \\ ${ }^{2}$ Assistant Professor, Dept. of Food \& Nutrition, Institute of Home Economics, Delhi University \\ Corresponding Author \\ Preeti Khanna
}

Institute of Home Economics, Delhi University

Email: preetikhanna.k@gmail.com

\begin{abstract}
Background: In order to understand eating behaviour of adolescents, insight into determinants of intake is necessary. Research has shown that anxiety and depression are associated with an increased risk for diabetes type 2, partly through their association with obesity and the metabolic syndrome, whereas both behavioral and biological mechanisms mediate such relations. Findings from existing research suggest that a more comprehensive approach to children \& adolescents with obesity may provide novel methods of obesity management.
\end{abstract}

Methods: Relevant Papers were identified from PubMed, Science Direct, Google Scholar, NCBI \& Medline by using all combinations of the search terms: "mental health, dietary intake, eating disorders, obesity, underweight or adolescents \& children". Research studies examining the relationship between mental health \& food intake among children \& adolescents were included in the review process. Based on inclusion - exclusion criteria full text papers were reviewed.

Results: A number of behavioral and emotional parameters connect obesity to anxiety and depression in children. Similarly to adults, children suffering from anxiety and/or depression are typically characterized by poor adherence to self-care activities, by sedentary habits and lack of physical exercise, excessive television and internet viewing and disturbed eating behaviors, such as emotional eating and consumption of comfort foods. The association between diet and depression has previously mainly been studied in cross sectional studies, and only few prospective studies have been published. The evidence suggests that folate and long-chain n-3 polyunsaturated fatty acids (PUFAs) may be connected to the decreased risk of depression. Furthermore, only few studies have concentrated on the association between general dietary patterns and depression.

Conclusion: Dietary intake may also have a direct impact on various biological systems and mechanisms that underpin depression, including oxidative processes, the functioning of the immune system, and levels of salient brain proteins. While considering the role of diet \& depression, several points need to be considered. First, in general, evidence has been found for the effects of isolated nutrients or foods, and not for dietary

patterns. Second, most previous studies have a cross-sectional design. Third, information is generally collected though questionnaires, increasing the risk of misclassification bias. Fourth, adequate control of confounding factors in observational studies is mandatory.

Keywords- Mental Health, Eating Disorders, Food intake, Adolescents \& children, Obesity \& Underweight. 


\section{INTRODUCTION}

Adolescence is a critical period for mental disorders, with a high percentage of all lifetime mental disorders detected for the first time by age 14 years (Kessler et al., 2005). During this period, mental health is strongly related to other developmental and health conditions. Investigations of clinic and community samples report that depression in adolescence can predict further problems by influencing quality of life, academic performance, social activities and even obesity in later life (Goodman \& Whitaker., 2002). Because the prevalence of mental disorders is high and causes effects on the physiological and psychological development of adolescents, the prevalence of mental disorders has become a major health problem (Patel et al., 2007). Therefore, it is necessary to understand potential risk factors for mental health disorders in young people in an effort to formulate appropriate measures for early prevention and intervention.

Diet is usually investigated in lifestyle-mediated diseases (Hu F et al., 2001). In recent years, dietary patterns have been the subject of increased attention in the field of adolescent mental health. Researchers noticed that inadequate nutrition and poor diet quality (fast food, confectionery items, animal foods) are more frequently associated with mental problems(Robinson et al., 2011;Molteni et al., 2002; Jacka et al., 2010; Howard et al., 2011). A crosssectional relationship between diet quality and depression was verified in a large sample of adolescents from a diverse range of sociodemographic backgrounds (Jacka et al., 2010).

The intakes of fruit, vegetables, meat, snacks and other healthy foods were also assessed and shown to be related with mental or physical disorders in adolescents (Robinson et al., 2011; Li Y et al., 2009; O'Sullivan et al., 2009). Unlike other diet research methods, dietary pattern analysis is used for characterizing the whole diet in combination. The use of FFQ has been validated in adolescents, sometimes even better than the $24 \mathrm{~h}$ recall approach (Slater et al., 2010). FFQ can capture complex behaviours and potentially interactive effects among special nutrients that might impact mental health (Jones-McLean et al., 2010). However, there are only a limited number of studies evaluating the association between special dietary patterns and mental disorders in adolescents (Robinson et al., 2011; Oddy et al., 2009). For example, in a recent study conducted in adolescents aged 13-15 years, Oddy et al. suggested that an increased adherence to a Western dietary pattern was associated with higher scores on the Child Behavior Checklist (CBCL), resulting in poorer mental health.

Adolescence is a stage when independence is established. Certain dietary patterns may be adapted by adolescents and might be followed for a long period. Consequently, unhealthy dietary patterns during youth would have profound implications for well-being in adulthood. In China the lifestyle and dietary habits of adolescents have changed in recent decades. Specifically, a higher percentage of urban adolescents consume more fast foods and sweetened beverages(Wang et al., 2008). There are few studies that have assessed the role of dietary patterns with respect to adolescent mental health in China.

Overall diet quality, as measured by these dietary pattern scores, has been shown to be crosssectionally related to clinical mood and anxiety disorders in a representative sample of Australian women. Higher scores on the healthy dietary pattern, characterized by vegetables, fruit, lean red meats, wholegrains and fish consumption, were associated with reduced odds for major depression, dysthymia, bipolar disorder and anxiety disorders, while higher scores on the 'western' dietary pattern, characterized by an increased consumption of unhealthy and processed foods, were associated greater odds for major depression, dysthymia and bipolar disorder (Jacka et al., 2010; Jacka et al., 2011). Similarly, Nanri et al. (2010) found that a healthy Japanese pattern, comprising higher intakes of vegetables, fruit, mushrooms and soy products, was inversely related to depressive symptoms in Japanese public servants. In the one prospective study conducted to date using dietary pattern analysis, Akbaraly et al. (2009) used data from the Whitehall II cohort to demonstrate that a 'whole food' dietary pattern, 
indicating greater consumption of nutrient-dense foods such as vegetables, fruits and fish, was inversely related to the risk for self-reported depression five years later. Conversely, a 'processed food' pattern, characterized by sweetened desserts, fried food, processed meat, and refined carbohydrates, was positively related to the risk for later depression.

Although the findings from observational studies have been largely consistent, evidence of mediation via biological mechanisms and data from intervention studies are currently lacking (Jacka et al., 2012). As such, it is still an unresolved question as to whether there is a true, biologically causal link between diet and mental health (Jacka et al., 2012). For example, it is plausible that differences in socioeconomic position, reflecting individuals' relative place within the structure of society and assessed by a range of measures of socioeconomic circumstances, such as educational level, economic disadvantage and occupational status, may explain the association observed between diet and depression risk. The fact that different measures of socioeconomic position have been shown to be inversely related to both diet quality (Galobardes et al., 2001) also reviewed in (Darmon \& Drewnowski., 2008) and risk for depression (Butterworth et al., 2012) is consistent with this hypothesis. While most previous studies in this field have included measures of socioeconomic circumstances in their analyses and largely excluded them as explanatory variables (e.g. marital and employment status (Sanchez-Villegas et al., 2009) ; education and area-level measures of advantage and disadvantage (Jacka et al., 2010); marital status, job title and position (Nanri et al., 2010); marital status, employment grade and education (Akbaraly et al., 2009); and income and education (Jack et al., 2011), there is always the possibility that the variables used did not capture all salient aspects of socioeconomic position or even that diet quality provides an explanation of the association between socioeconomic position and depression (ie. low socioeconomic position leading to poorer diet quality which, in turn, predisposes to depression). It is also possible that the association between diet quality and mental health reflects the comorbidity between physical and mental health. Diet quality is a risk factor for CVD and other chronic physical health conditions, which are also correlated with depression (Berk \& Jacka., 2012).

\section{METHODOLGY}

Relevant articles were identified by searching the PubMed, Science Direct, Google Scholar, NCBI \& Medline databases. Research articles published between Jan.2000 and Jan. 2014 which included cross-sectional, behavioural, observation \& longitudinal studies were selected. Key words such as "Food intake", "adolescents", "mental health", "dietary intake", "eating disorders", "obesity" and "underweight" were used in search strategy (Figu 1).

\section{Inclusion - Exclusion Criteria}

Studies considered for inclusion in this review (1) were full-text articles; (2) ) Published in English (3) conducted on adolescents \& children (4) examined association between diet quality or patterns with mental health assessed via self- or informant report, medical records, or the application of diagnostic measurement (5) used clinical study samples that were population. We excluded studies that

- examined individual multi-nutritional supplements \& preservatives on mental health

- examined the effects of medication on mental health

- used trait-based (assessing personality) or measures of stress (as distinct from internalizing behaviors)

- were published in languages other than English 
Fig.1: Flowchart of study selection process

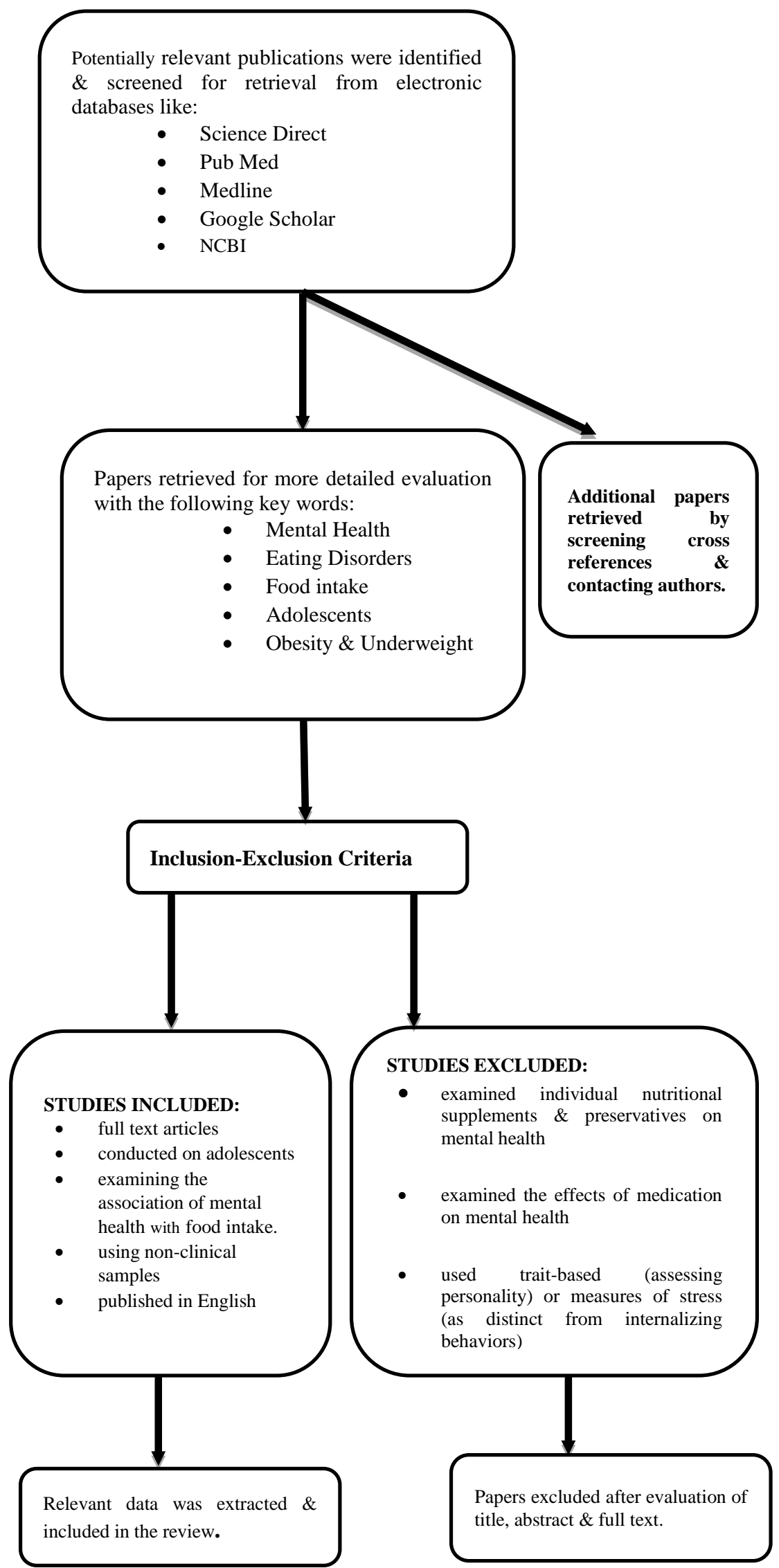




\section{RESULTS}

The World Health Organization (WHO) recognises mental health as a major health issue for adolescents and predicts that mental health problems will be one of the most serious global health problems by 2020 (World Health Organization 2005). Therefore investigating factors that influence mental health as expressed in behaviour and mood in young people is a high priority.

The limited literature to date suggests that poor nutrition is associated with adverse mental health, however the precise relationships between diet and mental health remain undefined (Tanskanen et al., 2001; Sublette et al., 2006). Alongside the emergence of child and adolescent mental health concerns, there have been radical changes in the diets of young people (Popkin and Gordon-Larsen, 2004) as well as global increases in the number of children and adolescents who are overweight or obese (Wang and Lobstein, 2006).

There is evidence to suggest that relationships exist between common mood or behavioural disorders and eating patterns, for example, a healthy diet has been associated with better mood and cognition in older adults (Samieri et al., 2008). However, very little research in adolescents has been reported and more investigations have been recommended (Bamber et al., 2007). Investigating dietary patterns has important public health implications because dietary intake is modifiable. Further, dietary pattern analysis provides an overall view of the diet that is not observed when evaluating individual nutrients alone. Given the personal, societal and economic costs of mental health and mood disorders during adolescence, the potential role of diet in moderating these conditions is an area worthy of exploration.

\section{MECHANISM LINKING DIET \& DEPRESSION}

Diet influences the biological and neurochemical actions in the body that may affect the development and progression of depression. Diet has been found to be involved in monoamine synthesis and inflammation, as well as to affect the HPA axis, neurogenesis and neural network functioning. Two most commonly studied nutrients possibly related to depression are folate and n-3 PUFAs, especially EPA and DHA (Sanhueza et al., 2012). In addition, several other nutrients, such as other group B vitamins, like vitamin B6 and B12 (Skarupski et al., 2010), vitamin D (Maddock et al., 2013), and the amino acid trypthophan (Shabbir et al., 2013) and foods like fish, olive oil, fruits and vegetables, and healthy and unhealthy dietary patterns have been connected to the risk of depression.

\section{Folate, Vitamin B.12 \& Depression}

Folate and vitamin B12 (cobalamin) belong to the group B water-soluble vitamins. Folate presents in many forms, such as tetrahydrofolate and methylenetetrahydrofolate, or folic acid and folinic acid (the two synthesized forms of folate). Adequate intake of folate is important for the formation of the neural tube after conception of the fetus, development of the brain and nervous system, normal growth, nucleotide synthesis as well as programmed cell death.

In psychiatric patients, deficiency of folate affects as many as one-third of the individuals, which may be explained by disturbed appetite, lowered intake, altered absorption or increased requirement (Mischoulon \& Rabb., 2007). Two thirds of individuals with megaloblastic anemia have been documented to have neuropsychiatric problems, and depression is the most common neuropsychiatric manifestation of folate deficiency (Reynolds EH., 2002). Depressed individuals have been observed to have lower circulating concentrations of folate and lower intake or concentrations of vitamin B12 (Robinson et al., 2011) compared to non-depressed individuals. However, even though low folate status and depression are connected, there is limited evidence concerning the direction of the association. Deficiency of folate can cause irregularities in methylation and synthesis of monoamine neurotransmitters. Folate forms share an inter conversion potential and are present in the pathways of one-carbon cycles impacting the synthesis of norepinephrine, dopamine and serotonin (Bottiglieri T., 2005). In detail, MTHF regulates the formation 
of tetra hydrobiopterin, which is a critical cofactor essential in the synthesis of neurotransmitters. MTHF indirectly regulates the levels of monoamines in CNS as deficiency of folate impairs the synthesis of tetrahydrobiopterin $(\mathrm{Ng}$ et al., 2009).However, these reactions in CNS are also dependent on the availability of B12 and homocysteine.

Folate in MTHF form is needed in the methylation reactions to reverse homocysteine, a sulphurated amino acid, back to methionine. Homocysteine is derived from dietary methionine, which is present in meat, fish, cheese, eggs and poultry. Elevated blood homocysteine is a functional marker of both folate and vitamin B12 deficiency. Homocysteine concentrations are usually higher among elderly people and in men compared to women. In addition to the influence on the monoamine metabolism, homocysteine is suggested to have neurotoxic effects. High blood concentrations of homocysteine have been associated with elevated prevalence of depression (Bjelland et al., 2003).

Nevertheless, as low blood concentrations of folate, vitamin B12 and high blood concentrations of homocysteine are highly connected, it is difficult to distinguish which of them is more important in terms of depression. MTHF is also required in the synthesis of S-adenosyl-methionine (SAMe), the vital methyl donor in several methylation reactions. SAMe has been suggested to have independent antidepressant properties and to be more effective than placebo and equally effective with tricyclic antidepressants with fewer side effects in the treatment of depression (Mischoulon \& Fava., 2002). The dose-response rate and mechanisms behind SAMe's possible effects on depressive symptoms are still partly unrecognized, and hence SAMe is regarded with caution.

\section{n-3 Polyunsaturated Fatty Acids \& Depression}

PUFAs are typically classified into n-3 (or omega-3) and n-6 (or omega-6) fatty acids. N-3 PUFAs are a family of PUFAs, named due to the positioning of the first double carbon bond on the third atom from the methyl end of the acyl chain. The role of the n-3
PUFAs is important in the development of the nervous system, blood vessels and skin. Moreover, n-3 PUFAs are present in the synthesis of eicosanoids and needed in the aggregation of thrombocytes, regulation of blood pressure and inflammation, and defense reactions of the body. In addition, long-chain PUFAs are needed in the cell membranes of CNS and retina of the eyes. The long-chain n-3 PUFAs, EPA and DHA, are the major bioactive components of n-3 PUFAs, but also docosapentaenoic acid (DPA), which is in a minor role, is included in the long-chain n-3 PUFAs (Tur et al., 2012).

Increasing evidence suggests that depletion of n-3 PUFAs may play an etiological role in several inflammatory and neuropsychiatric disorders including depression. Depressed individuals have been shown to have lower intake or concentrations of n-3 PUFAs compared to non-depressed individuals in some, but not in all studies (Hakkarainen et al., 2004).

N-3 PUFAs are involved in, or modulate, the mechanism by which brain neurons communicate. DHA(Decosahexanoic Acid) is the predominant fatty acid in the brain (approximately 15\% of fatty acids), whereas EPA(Eicosapentenoic Acid) exists in the brain to a lesser extent (approximately $0.2 \%$ of fatty acids). Therefore, DHA concentration especially affects the permeability of membrane cells in CNS and deficiency of DHA has been found to relate to dysfunctions and impaired transmission of serotonin, norepinephrine and dopamine (Su KP., 2009).Phospholipids of neural cell membrane consist especially of PUFAs. N-3 PUFAs and fish consumption have been connected to the inflammation theory. Traditionally, a high ratio of n-6 to n-3 has been thought to enhance proinflammatory cytokine production, whereas n-3 PUFAs as such have anti-inflammatory properties. Fish intake $>150$ grams/week has been linked to decreased levels of proinflammatory markers, such as CRP and cytokines, like interleukin-6, which supports the hypothesis that eating more fish could lead to altered depressive symptoms through the 
modification of inflammation process (Bountziouka et al., 2009).

Different PUFAs may have different effects on eicosanoid production. The details of this process have been presented in more detail elsewhere. In summary, AA (Arachidonic Acid), an n-6 fatty acid, can be metabolized to proinflammatory eicosanoids, whereas ALA (Alpha Linolenic Acid), an n-3 fatty acid, can be converted to EPA, which can be further converted to anti-inflammatory eicosanoids. Higher dietary intake of ALA has been found to associate with lower plasma levels of inflammatory biomarkers. EPA and DHA reduce inflammation by decreasing the effect on the synthesis of eicosanoids by competing with AA (Mamalakis et al., 2009).

\section{ASSOCIATION OF DIETARY PATTERNS, OBESITY \& MENTAL HEALTH}

\section{Depression \& Anxiety}

In recent times there has been an increasing focus on the possible links between diet quality and the common mental disorders, depression and anxiety.

Overall diet quality, as measured by these dietary pattern scores, has been shown to be crosssectionally related to clinical mood and anxiety disorders in a representative sample of Australian women. Higher scores on the healthy dietary pattern, characterized by vegetables, fruit, lean red meats, wholegrains and fish consumption, were associated with reduced odds for major depression, dysthymia, bipolar disorder and anxiety disorders, while higher scores on the 'western' dietary pattern, characterized by an increased consumption of unhealthy and processed foods, were associated greater odds for major depression, dysthymia and bipolar disorder (Jack et al., 2010). Similarly, Nanri et al. (2010) found that a healthy Japanese pattern, comprising higher intakes of vegetables, fruit, mushrooms and soy products, was inversely related to depressive symptoms in Japanese public servants.

Research suggests that for older people, a diet low in healthy foods and/or a diet high in unhealthy foods may increase the risk of depression over time. Importantly, the predictive effect of dietary patterns on later depressive symptoms persisted after controlling for a robust indicator of socioeconomic position, as well as baseline depressive symptoms and lifestyle and cardiovascular risk factors. This supports the contention that poor diet quality imposes its own risk for depression, independently of socioeconomic circumstances. This also receives support from the finding that dietary patterns did not explain the association between socioeconomic position and depressive symptoms (Butterworth et al., 2010).

Finally, there was no evidence in any of the analyses that the two variables representing western and prudent dietary patterns interacted to jointly influence depressive scores, which is consistent with the view that reduced intake of healthy foods is a risk factor for poor mental health in older adults, regardless of the intake of unhealthy foods, and vice versa.

Although we cannot be sure of why the predictive effect of dietary patterns on depressive scores was only evident in the older cohort and not in the younger and middle-aged cohorts, one possible explanation relates to the chronic impact of poor quality diet on the biological systems that affect depression risk, with the cumulative effects of poor diet only impacting on mood in later life. For example, while the long-term effects of poor diet lead to conditions associated with chronic inflammation (eg. Visceral obesity), and vascular pathology (e.g. atherosclerosis), these effects are likely to develop over decades and their impact on brain function may not be detectable until later in life. As such, the predictive relationship of poor quality diet, characterized by these dietary pattern scores, on the incidence of depressive symptoms may reflect the long-term exposure to the noxious effects of high fat, refined sugar foods and/or a diet insufficient in nutrients and fibre.

Dietary intake may also have a direct impact on various biological systems and mechanisms that underpin depression, including oxidative processes, the functioning of the immune system, and levels of salient brain proteins. For example, in patients with depression, markers of systemic inflammation are often significantly greater than in controls, which is 
indicative of immune system dysregulation (Irwin \& Miller., 2007). Studies have indicated that markers of inflammation are positively correlated with components of a poor diet, and a healthy diet is associated with reduced inflammation (Esposito et al., 2004) The available evidence also suggests that high-fat, high-sugar diets can affect proteins that are important in brain development, such as the signaling molecule brain-derived neurotrophic factor (Molteni et al., 2004). Brain-derived neurotrophic factor is often reduced in patients with depression, (Bocchio-Chiavetto et al., 2010) and when its synthesis is increased, symptoms of depression can improve ( Brunoni et al., 2008).It is important to note that consistent evidence has shown that higher quality diets (i.e., those higher in nutrient-dense foods) and diets high in saturated fats and refined carbohydrates are each independently related to depression, suggesting the possibility of different operant pathways. The correlation between healthy and unhealthy dietary patterns is also weak (Jacka et al.). However, we acknowledge that these interpretations remain speculative in view of the limited evidence for causality currently available.

\section{Attention -Deficit/Hyperactivity Disorder (ADHD)}

Attention-deficit/hyperactivity disorder (ADHD) is characterized by inattention, hyperactivity, and impulsivity (Bauchner H., 2002) and is the most prevalent mental health disorder in childhood. While there are many clinical and epidemiological publications on the association between ADHD or ADHD symptoms and overweight/ obesity (Holtkamp et al., 2004; Braet et al., 2007) the literature on the association between ADHD symptoms and energy balance related behaviors such as physical activity, television exposure, and food and beverage intake is scarce. It has been suggested, though not empirically proven, that impulsive children tend to overeat in an obesogenic environment (Nederkoon et al., 2006; Nederkoon et al., 2006; Guerrieri et al., 2008). In one crosssectional study in 375 school-aged children, ADHD was significantly associated with increased intake of sweets and fast-food measured by a semiquantitative food-frequency questionnaire (Azadbakht \& Esmaillzadeh., 2012). Factor analysis of dietary data revealed that adolescents with ADHD were likely to consume a "Western" diet high in saturated and total fat and refined sugar while low in fiber, but unlikely to consume a Mediterranean diet rich in fish, vegetables, fruit, legumes, and whole-grain foods after adjusting for known confounding factors (Howard et al., 2011).

Animal, genetic and neuroimaging studies suggest that the dopaminergic system plays a role in both the neurobiology of ADHD as well as in the reward system of food-seeking behaviour. Therefore, one may hypothesize that factors that are believed to contribute to children's ADHD symptoms also affect their reward system for food and therefore change the appetizing value of certain food stimuli resulting in an increased food intake.

In sum, ADHD children may represent a population that expresses both higher rates of lifestyle activity and obesity.

There is evidence that overweight/obese children have a significantly higher risk for ADHD symptoms than normal weight children. Also preventive efforts to promote healthy behaviors will have to address the network of associations between ADHD symptoms, health behaviors, overweight/ obesity, and parental variables.

In sum, these studies imply that at least in a subgroup of obese patients behavioural problems may be involved in the development or maintenance of overweight and obesity. Impulsive behaviour is a symptom of ADHD, conduct disorder and oppositional defiant disorder and as such may play a role in the development of obesity in ADHD children.

\section{ASSOCIATION OF EATING DISORDERS, DIETING BEHAVIOURS \& MENTAL HEALTH}

Adolescence is regarded as a period of developmental risk for eating disorders (Stice et al., 2009; Isoma et al., 2009) and eating disorder symptoms [Abebe et al., 2011; Steinhausen et al., 
2005; Neumark-Sztainer et al., 2011). In general, eating disorder symptoms increase from 14-16 years in females (Abebe et al., 2011; Steinhausen et al., 2005), with peaks in binge eating onset at 16-17 years and purging onset at 17-18 years (Stice et al., 2009). Few studies have considered the developmental trajectory of eating disorder symptoms in males, but available data suggest that boys may show reductions in eating pathology from early adolescence to mid adolescence, and then experience an increase in symptoms in late adolescence or early adulthood (Keel et al., 2013; Sonneville et al., 2007).

Eating disorders and eating disorder symptoms are strongly associated with other mental health difficulties, including depression, anxiety, substance misuse, and personality disorders (Godart et al., 2007; Swanson et al., 2011). These associations are particularly well documented for depression (Godart et al., 2007) and it has been established that depression and eating disorder symptoms show a bidirectional relationship, with each predicting increases in the other over time. Most of this research has been conducted with females (Marmorstein et al., 2008; Silberg et al., 2005), but Sonneville and colleagues found significant associations between binge eating behaviour and later onset of depressive symptoms in male ( $\mathrm{n}=$ $7843)$ and female $(n=9039)$ participants followed from adolescence to young adulthood in the Growing Up Today Study (GUTS) (Sonneville et al., 2013).

In the BELLA study, $23 \%$ of 14- to 17-year-olds reported abnormal eating behavior (HerpertzDahlmann et al., 2008), which, however, might not necessarily fulfill all classification criteria of a fullblown eating disorder.About $40 \%$ of all new cases of anorexia nervosa arise in early to midadolescence (Hoel., 2006); the incidence peak of bulimia nervosa is in mid- to late adolescence.

It is now thought that strict dieting may precipitate an eating disorder in a (genetically) vulnerable adolescent. The prognosis of anorexia nervosa in adolescence has markedly improved in recent years, but many former anorexics have other types of mental disorder in adulthood (Wentz et al., 2009). Some of these disorders may be the expression of "biological scars" that are left behind by anorexiainduced hormonal deficits and dysfunctions (e.g., estrogen and thyroxine deficiency, hypercortisolism) during the adolescent phase of brain development (Herpertz-Dahlmann et al., 2011).

Dieting, subthreshold eating-disordered disturbance, and childhood obesity each has been identified as risk factors for the development of eating disorders However, the timing of their manifestation and the interactions between these risk factors in the development of eating and/or weight problems have remained largely unexplored in middle childhood.

Dieting in childhood is not uncommon and it has been reported that children as young as 8 years old engage in dieting behaviors. Both retrospective and prospective studies in adolescents have found selfreported dieting to predict bulimic symptoms and eating-related psychopathology Such results have been interpreted as consistent with restraint theory, which posits that dietary restriction should increase the risk for the onset of binge eating and bulimic pathology. Although children with greater body mass are more likely to diet in proportion to their degree of obesity, little is know about the relationship between dieting and disturbed eating in young overweight children, when dieting behaviors may first emerge.

Binge eating has also been found to occur before adolescence. Whether assessed by self-report questionnaires (Morgan et al., 2002) or interview methodology (Tanofsky-Kraff et al., 2004), the experience of loss of control (LOC) while eating, as opposed to the amount of food eaten, has been found to be significantly related to elevations in disturbed eating cognitions, depressive symptoms and anxiety, and to body adiposity. Among preadolescent children, those who are overweight are also significantly more likely to engage in LOC eating behaviors than their normal-weight counterparts (Tanofsky-Kraff et al., 2004).

Retrospective studies of overweight adults with binge eating disorder (BED) examining the perceived onset of dieting and binge eating suggest 
that different potential pathways to BED exist. In one path, dieting precedes the development of binge eating behavior, whereas along another path, binge eating appears to develop before dieting (Grilo \& Masheb, 2000). For adult patients who reported binge eating before the onset of dieting behavior ( $\leq$ $50 \%$ of participants across studies), binge eating was described as first occurring between the ages of 11 and 13 years. Furthermore, those who reported early onset of binge eating met the criteria for BED at an earlier age (Grilo \& Masheb, 2000) and had a greater lifetime history of psychiatric disturbance than patients who remembered dieting before binge eating. Finally, early reported onset of binge eating (at age $\leq 16$ years) has been associated with poor treatment outcome (Safer, Lively, Telch, \& Agras, 2002). Such findings are not consistent with restraint theory and have promoted researchers to examine other theoretical models that might explain the development of BED when binge eating occurs before the development of dieting.

Given that young, overweight children appear to be at greater risk than normal-weight children for dieting and LOC eating, examining the perceived temporal sequence of these behaviors may provide intervention targets for the prevention of greater eating disturbance or inappropriate weight gain. Our primary aim was to relate the sequence \& mechanism of self-reported dieting, LOC eating, and overweight to differences in eating-disordered cognitions, depressive symptoms \& anxiety.

\section{DISCUSSIONS}

Our aim was to review and integrate the existing literature to determine whether an association exists between diet quality and mental health in childhood $\&$ adolescence, with a focus on internalizing disorders including depression, \& anxiety. We found consistent associations between unhealthy eating patterns, obesity, eating disorders \& mental health. Overall evidence suggest that there is a lack of research data available in this regard.

These findings add to the limited literature that has attempted to establish an association between diet (diet quality) \& mental health in adolescents \& children.

It may be the case that children and adolescents with internalizing disorders or symptoms eat more poorly as a form of self-medication. However, it is equally as conceivable that the influence of early eating habits and nutritional intake has an important impact on affect. Indeed, there are numerous potential biological pathways by which diet quality may have an impact on mental health in children and adolescents. First, a poor quality diet that is lacking nutrient-dense foods may lead to nutrient deficiencies that have been associated with mental health issues. For example, the dietary intake of folate, zinc, and magnesium is inversely associated with depressive disorders whereas dietary longchain omega-3 fatty acids are inversely related to anxiety disorders (Jacka et al., 2013).

Dietary intake may also have a direct impact on various biological systems and mechanisms that underpin depression, including oxidative processes, the functioning of the immune system, and levels of salient brain proteins.

Despite a paucity of data, the review highlights the potential importance of the relationship between dietary patterns \& quality with mental health during the developmental phase of adolescence. While considering the role of diet $\&$ depression, several points need to be considered. First, in general, evidence has been found for the effects of isolated nutrients or foods, and not for dietary patterns. Second, most previous studies have a crosssectional design. Third, information is generally collected though questionnaires, increasing the risk of misclassification bias. Fourth, adequate control of confounding factors in observational studies is mandatory.

Prospective and intervention studies are now required to improve the level of evidence. Given that the average age of onset for anxiety and mood disorders is 6 years and 13 years, respectively (Merikangas et al., 2010) the potential for early intervention using strategies targeted at improving dietary intake at a population level may be of substantial public health benefit. However, this 
would require policy action to improve the global food environment (Jacka et al., 2014).

\section{REFERENCES}

1. Abebe DS, Lien L, Von Soest R. The development of bulimic symptoms from adolescence to young adulthood in females and males: a population-based longitudinal cohort study. Int J Eat Disord. 2012;1:737745. doi:10.1002/eat.20950.

2. Abramson JL, Hooper WC, Jones DP, Ashfaqc S, Rhodes SD, et al. (2005) Association between novel oxidative stress markers and C-reactive protein among adults without clinical coronary heart disease. Atherosclerosis 178: 115- 121.

3. adults: the Hordaland Health study. Psychosom Med 73: 483-490.

4. Akbaraly TN, Brunner EJ, Ferrie JE, Marmot MG, Kivimaki M, et al. (2009) Dietary pattern and depressive symptoms in middle age. Br J Psychiatry 195: 408-413.

5. Bamber, D.J., Stokes, C.S., Stephen, A.M., 2007. The role of diet in the prevention and management of adolescent depression. Nutr. Bull. 32 (s1), 90-99.

6. Bauchner H (2000) ADHD: A new practice guideline from the American Academy of Pediatrics. Attention deficit hyperactive disorder. Arch Dis Child 83: 63.

7. Bauchner H (2000) ADHD: A new practice guideline from the American Academy of Pediatrics. Attention deficit hyperactive disorder. Arch Dis Child 83: 63.. Holtkamp K, Konrad K, Muller B, Heussen N, Herpertz S, et al. (2004) Overweight and obesity in children with AttentionDeficit/Hyperactivity Disorder. Int J Obes Relat Metab Disord 28: 685-689.

8. Baune BT, Ponath G, Rothermundt M, Roesler A, Berger K (2009) Association between cytokines and cerebral MRI changes in the aging brain. J Geriatr Psychiatry Neurol 22: 23-34.
9. Berk M, Jacka FN (2012) Preventive strategies in depression: gathering evidence for risk factors and potential interventions. British journal of psychiatry 201: 339-341.

10. Biederman J, Faraone SV. Current concepts on the neurobiology of AttentionDeficit/Hyperactivity. J Atten Disord Suppl 2002; 6/1: 7-16.

11. Bjelland I, Tell G, Vollset S, Refsum H, Ueland P. Folate, vitamin B-12, homocysteine, and the MTHFR 677C -> T polymorphism in anxiety and depression The Hordaland Homocysteine Study. Arch Gen Psychiatry 2003;60:618-626.

12. Bocchio-Chiavetto L, Bagnardi V, Zanardini R. et al. Serum and plasma BDNF levels in major depression: a replication study and meta-analyses. World J Biol Psychiatry. 2010;11(6):763-773.

13. Bottiglieri T. Homocysteine and folate metabolism in depression. Prog Neuropsychopharmacol Biol Psychiatry 2005;29:1103-1112.

14. Bountziouka V, Polychronopoulos E, Zeimbekis A, Papavenetiou E, Ladoukaki E, Papairakleous N, Gotsis E, Metallinos G, Lionis C, Panagiotakos D. Long-term fish intake is associated with less severe depressive symptoms among elderly men and women: the MEDIS (MEDiterranean ISlands Elderly) epidemiological study. J Aging Health 2009;21:864-880.

15. Braet C, Claus L, Verbeken S, Van Vlierberghe L (2007) Impulsivity in overweight children. Eur Child Adolesc Psychiatry 16: 473-483.

16. Braet C, Claus L, Verbeken S, Van Vlierberghe L (2007) Impulsivity in overweight children. Eur Child Adolesc Psychiatry 16: 473-483.

17. Brunoni AR, Lopes M, Fregni F. A systematic review and meta-analysis of clinical studies on major depression and BDNF levels: implications for the role of neuroplasticity in depression. Int $\mathbf{J}$ 
Neuropsychopharmacol. $\quad 2008 ; 11(8)$ :11691180.

18. Burstein M, Ameli-Grillon L, Merikangas KR: Shyness versus social phobia in US youth. Pediatrics 2011; 128: 917-25.

19. Butterworth P, Olesen SC, Leach LS (2012) The role of hardship in the association between socio-economic position and depression. The Australian and New Zealand journal of psychiatry 46: 364-373.

20. Butterworth P, Olesen SC, Leach LS (2012) The role of hardship in the association between socio-economic position and depression. The Australian and New Zealand journal of psychiatry 46: 364-373.

21. ciated psychopathology and health-related quality of life: results of the BELLA study. Eur Child Adolesc Psychiatry 2008; 17 Suppl 1: 82-91

22. Costello EJ, Copeland W, Angold A: Trends in psychopathology across the adolescent years: what changes when children become adolescents, and when adolescents become adults? J Child Psychol Psychiatry 2011; 52: 1015-25.

23. Darmon N, Drewnowski A (2008) Does social class predict diet quality? The American journal of clinical nutrition 87: 1107-1117.

24. Du MY, Wu QZ, Yue Q, Li J, Liao Y, et al. (2012) Voxelwise meta-analysis of gray matter reduction in major depressive disorder. Prog Neuropsychopharmacol Biol Psychiatry 36: 11-16.

25. Esposito K, Marfella R, Ciotola M. et al. Effect of a Mediterranean-style diet on endothelial dysfunction and markers of vascular inflammation in the metabolic syndrome: a randomized trial. JAMA.2004;292(12):1440-1446.

26. Esposito K, Nappo F, Marfella R, Giugliano G, Giugliano F, et al. (2002) Inflammatory cytokine concentrations are acutely increased by hyperglycemia in humans: role of oxidative stress. Circulation 106: $2067-$ 2072.

27. Essau CA, Conradt J, Petermann F: Incidence of post-traumatic stress disorder in adolescents: results of the Bremen Adolescent Study. Z Kinder Jugendpsychiatr Psychother 1999; 27: 37-45.

28. Essau CA, Petermann F: Anxiety disorders in children and adolescents. Epidemiology, risk factors and intervention. MMW Fortschr Med 1999; 141: 32-5.

29. Galobardes B, Morabia A, Bernstein MS (2001) Diet and socioeconomic position: does the use of different indicators matter? Int J Epidemiol 30: 334- 340.

30. Gerecke KM, Kolobova A, Allen S, Fawer JL (2013) Exercise protects against chronic restraint stress-induced oxidative stress in the cortex and hippocampus. Brain Res.

31. Giedd JN, Blumenthal J, Jeffries NO, et al.: Brain development during childhood and adolescence: a longitudinal MRI study. Nat Neurosci 1999; 2: 861-3.

32. Godart NT, Perdereau F, Rein Z, Berthoz S, Wallier J, Jeammet P, Flament MF. Comorbidity studies of eating disorders and mood disorders: critical review of the literature. J Affect Disord.2007;1:37-49. doi: 10.1016/j.jad.2006.06.023.

33. Goodman E \& Whitaker RC (2002) A prospective study of the role of depression in the development and persistence of adolescent obesity. Pediatrics 110, 497-504.

34. Guenther PM, Reedy J, Krebs-Smith SM, Reeve BB, Basiotis PP (2007) Development and Evaluation of the Healthy Eating Index2005: Technical Report. U.S. Department of Agriculture.

35. Guerrieri R, Nederkoorn C, Jansen A (2008) The interaction between impulsivity and a varied food environment: its influence on food intake and overweight. Int $\mathrm{J}$ Obes (Lond) 32: 708-714.

36. Guerrieri R, Nederkoorn C, Jansen A (2008) The interaction between impulsivity and a 
varied food environment: its influence on food intake and

37. Hakkarainen R, Partonen T, Haukka J, Virtamo J, Albanes D, Lönnqvist J. Food and nutrient intake in

38. Halmi KA: Anorexia nervosa: an increasing problem in children and adolescents. Dialogues Clin Neurosci 2009; 11: 100-3.

39. Henderson L, Gregory J, Swan G (2002) The National Diet and Nutrition Survey: Adults Aged 19-64 Years: Types and Quantities of Foods Consumed.London.

40. Herpertz-Dahlmann B, Seitz J, Konrad K: Aetiology of anorexia nervosa: from a „psychosomatic family model" to a neuropsychiatric disorder?Eur Arch Psychiatry Clin Neurosci 2011; 261: 177-81.

41. Herpertz-Dahlmann B, Wille N, Hölling H, Vloet TD, Ravens-Sieberer U; BELLA study group: Disordered eating behaviour and attitudes, asso -

42. Herpertz-Dahlmann B: Psychiatrische Erkrankungen der Adoleszenz. In: Uhlhaas PJ, Konrad K (eds.): Das adoleszente Gehirn. Stuttgart: Kohlhammer 2011; 20622.

43. Hoek HW: Incidence, prevalence and mortality of anorexia nervosa and other eating disorders. Curr Opin Psychiatry 2006; 19: 389-94.

44. Holtkamp K, Konrad K, Muller B, Heussen N, Herpertz S, et al. (2004) Overweight and obesity in children with AttentionDeficit/Hyperactivity Disorder. Int J Obes Relat Metab Disord 28: 685-689.

45. Howard AL, Robinson M, Smith GJ et al. (2011) ADHD is associated with a 'Western' dietary pattern in adolescents. J Atten Disord 15, 403-411.

46. Howard AL, Robinson M, Smith GJ, Ambrosini GL, Piek JP, et al. (2011) ADHD is associated with a "Western" dietary pattern in adolescents. J Atten Disord 15: 403-411.
47. Hu F, Manson J, Stampfer M et al. (2001) Diet, lifestyle, and the risk of type 2 diabetes mellitus in women. N Engl J Med 345, 790797.

48. Irwin MR, Miller AH. Depressive disorders and immunity: 20 years of progress and discovery. Brain Behav Immun. 2007;21(4):374-383.

49. Isomaa $R$, Isomaa $A-L$, Marttunen $M$, Kaltiala-Heino R, Bjorkqvist $\mathrm{K}$. The prevalence, incidence and development of eating disorders in Finnish adolescents-A two-step 3-year follow-up study. Eur Eat Disord Rev. 2009;1:199-207. doi: 10.1002/erv.919.

50. Jacka FN, Cherbuin J, Anstey K, Butterworth P. Dietary patterns and depressive symptoms over time: examining the relationships with socioeconomic position, health behaviours and cardiovascular risk. PLoS One. 2014;9(1) e87657.

51. Jacka FN, Kremer PR, Leslie ER et al. (2010) Associations between diet quality and depressed mood in adolescents: results from the Australian Healthy Neighbourhoods Study. Aust N Z J Psychiatry 44, 435-442.

52. Jacka FN, Mykletun A, Berk M (2012) Moving towards a population health approach to the primary prevention of common mental disorders. BMC Medicine 10: 149 .

53. Jacka FN, Mykletun A, Berk M, Bjelland I, Tell GS (2011) The association between habitual diet quality and the common mental disorders in communitydwelling. Psychosomatic Medicine 2011, 73(6):483490.

54. Jacka FN, Pasco JA, Mykletun A, Williams LJ, Hodge AM, et al. (2010) Association between western and traditional diets and depression and anxiety in women. Am J Psychiatry 167: 305-311. 
55. Jacka FN, Pasco JA, Mykletun A, Williams LJ, Nicholson GC, et al. (2011) Diet quality in bipolar disorder in a population-based sample of women. J Affect Disord 129: 332337.

56. Jacka FN, Pasco JA, Williams LJ, Meyer BJ, Digger R, Berk M. Dietary intake of fish and PUFA, and clinical depressive and anxiety disorders in women. $\mathrm{Br} \mathrm{J}$ Nutr. 2013;109(11):2059-2066

57. Jacka FN, Sacks G, Berk M, Allender S. Food policies for physical and mental health. BMC Psychiatry.2014;14:132.

58. Jones-McLean E, Shatenstein B \& Whiting S (2010) Dietary patterns research and its applications to nutrition policy for the prevention of chronic disease among diverse North American populations. Appl Physiol Nutr Metab 35, 195-198.

59. Keel PK, Baxter MG, Heatherton TF, Joiner TE. A 20-year longitudinal study of body weight, dieting, and eating disorder symptoms. J Abnorm Psychol. 2007;1:422432.

60. Kessler RC, Berglund P, Demler O et al. (2005) Lifetime prevalence and age-of-onset distributions of DSM-IV disorders in the National Comorbidity Survey Replication. Arch Gen Psychiatry 62, 593-602.

61. Konrad K, Firk C, Uhlhaas PJ: Brain development during adolescence: neuroscientific insights into this developmental period. Dtsch Arztebl Int 2013; 110 (25) 425-31.

62. Konrad K. Strukturelle Hirnentwicklung in der Adoleszenz. In: Uhlhaas PJ, Konrad K (eds.): Das adoleszente Gehirn. Stuttgart: Kohlhammer 2011; 124-38.

63. Leven I, Quenzel G, Hurrelmann K: Familie, Schule, Freizeit: Kontinuitätim Wandel. In: Shell Deutschland Holding (eds.): Jugend 2010. Frankfurtam Main: Fischer Taschenbuch Verlag 2010; 53-128.

64. Li Y, Zhang J \& McKeown RE (2009) Cross-sectional assessment of diet quality in individuals with a lifetime history of attempted suicide. Psychiatry Res 165, 111119.

65. Maddock J, Berry DJ, Geoffroy MC, Power C, Hypponen E. Vitamin D and common mental disorders in mid-life: Cross-sectional and prospective findings. Clin Nutr 2013 Jan 21.

66. Mamalakis G, Tornaritis M, Kafatos A. Depression and adipose essential polyunsaturated fatty acids. Prostaglandins Leukot Essent Fatty Acids 2002;67:311-318.

67. Marmorstein NR, von Ranson KM, lacono WG, Malone SM. Prospective associations between depressive symptoms and eating disorder symptoms among adolescent girls. Int J Eat Disord.2008;1(2):118-123. doi: 10.1002/eat.20477.

68. Maron D (2004) Flavonoids for reduction of atherosclerotic risk. Current Atherosclerosis Reports 6: 73-78.

69. Merikangas KR, He JP, Burstein M. et al. Lifetime prevalence of mental disorders in US adolescents: results from the National Comorbidity Survey Replication-Adolescent Supplement (NCS-A) J Am Acad Child Adolesc Psychiatry. 2010;49(10):980-989.

70. Mischoulon D, Fava M. Role of S-adenosylL-methionine in the treatment of depression: a review of the evidence. Am J Clin Nutr 2002;76:1158S-61S.

71. Mischoulon D, Raab MF. The role of folate in depression and dementia. $\mathbf{J}$ Clin Psychiatry 2007;68 Suppl 10:28-33.

72. Mohanty P, Ghanim H, Hamouda W, Aljada A, Garg R, et al. (2002) Both lipid and protein intakes stimulate increased generation of reactive oxygen species by polymorphonuclear leukocytes and mononuclear cells. Am J Clin Nutr 75: 767772.

73. Molteni R, Barnard R, Ying Z, Roberts C, Gomez-Pinilla F. A high-fat, refined sugar diet reduces hippocampal brain-derived neurotrophic factor, neuronal plasticity, and 
learning. Neuroscience.2002;112(4):803814.

74. Molteni R, Barnard RJ, Ying Z et al. (2002) A high-fat, refined sugar diet reduces hippocampal brain-derived neurotrophic factor, neuronal plasticity, and learning. Neuroscience 112, 803-814.

75. Nanri A, Kimura Y, Matsushita Y, Ohta M, Sato M, et al. (2010) Dietary patterns and depressive symptoms among Japanese men and women. Eur J Clin Nutr 64: 832-839.

76. Nanri A, Kimura Y, Matsushita Y, Ohta M, Sato M, et al. (2010) Dietary patterns and depressive symptoms among Japanese men and women. Eur J Clin Nutr 64: 832-839.

77. Nederkoorn C, Braet C, Van Eijs Y, Tanghe A, Jansen A (2006) Why obese children cannot resist food: the role of impulsivity. Eat Behav 7: 315-322.

78. Nederkoorn C, Braet C, Van Eijs Y, Tanghe A, Jansen A (2006) Why obese children cannot resist food: the role of impulsivity. Eat Behav 7: 315-322.

79. Nederkoorn C, Jansen E, Mulkens S, Jansen A (2006) Impulsivity predicts treatment outcome in obese children. Behav Res Ther 45: 1071-1075.

80. Nederkoorn C, Jansen E, Mulkens S, Jansen A (2006) Impulsivity predicts treatment outcome in obese children. Behav Res Ther 45: 1071-1075.

81. Neumark-Sztainer D, Wall M, Larson NI, Eisenberg ME, Loth K. Dieting and disordered eating behaviors from adolescence to young adulthood: Findings from a 10-year longitudinal study. J Am Diet Assoc. 2011;1:1004-1011. doi: 10.1016/j.jada.2011.04.012.

82. Ng TP, Feng L, Niti M, Kua EH, Yap KB. Folate, vitamin B12, homocysteine, and depressive symptoms in a population sample of older Chinese adults. J Am Geriatr Soc 2009;57:871-876.

83. O'Sullivan TA, Robinson M, Kendall GE et al. (2009) A good-quality breakfast is associated with better mental health in adolescence. Public Health Nutr 12, 249258.

84. Oddy WH, Robinson M, Ambrosini GL et al. (2009) The association between dietary patterns and mental health in early adolescence. Prev Med 49, 39-44.

85. Oerter R, Montada L: Entwicklungspsychologie, 5th edition. Weinheim: Beltz 2002.

86. of depression: the Seguimiento Universidad de Navarra/University of Navarra follow-up (SUN) cohort. Arch Gen Psychiatry 66: 1090-1098.

87. overweight. Int J Obes (Lond) 32: 708-714

88. Patel V, Flisher AJ, Hetrick S et al. (2007) Mental health of young people: a global public-health challenge. Lancet

89. Persike M, Seiffge-Krenke I: Competence in coping with stress in adolescents from three regions of the world. J Youth Adolesc 2012; 41: 863-79.

90. Popkin, B.M., Gordon-Larsen, P., 2004. The nutrition transition: worldwide obesity dynamics and their determinants. Int. J. Obes. 28 (3). Wang, Y., Lobstein, T., 2006. Worldwide trends in childhood overweight and obesity. Int. J. Pediatr. Obes. 1 (1), 11-25

91. predictor of long-term weight loss after inpatient treatment in obese adolescents. Int J Eat Disord. doi: 10.1002/eat.22043.

92. Psychiatry 163 (6), 1100-1102.

93. Rao JS, Kellom M, Kim HW, Rapoport SI, Reese EA (2012) Neuroinflammation and synaptic loss. Neurochem Res 37: 903-910.

94. Ravens-Sieberer U, Wille N, Bettge S, Erhart M: Mental health of children and adolescents in Germany. Results from the BELLA study within the German Health Interview and Examination Survey for Children and Adolescents (KiGGS). Bundesges undheitsblatt Gesundheitsforschung Gesundheitsschutz 2007; 50: 871-8. 
95. relation to mental wellbeing. Nutr $\mathrm{J}$ 2004;3:14.

96. Resch F, Parzer P, Brunner R, BELLA study group: Self-mutilation and suicidal behaviour in children and adolescents: prevalence and psychosocial correlates: results of the BELLA study. Eur Child Adolesc Psychiatry 2008; 17: 92-8.

97. Reynolds EH. Folic acid, ageing, depression, and dementia. BMJ 2002;324:1512-1515.

98. Riediger ND, Othman RA, Suh M, Moghadasian MH (2009) A systemic review of the roles of n-3 fatty acids in health and disease. J Am Diet Assoc 109: 668-679.

99. Robinson DJ, O'Luanaigh C, Tehee E, O'Connell H, Hamilton F, Chin AV, Coen R, Molloy AM, Scott J, Cunningham CJ, et al. Associations between holotranscobalamin, vitamin B12, homocysteine and depressive symptoms in community-dwelling elders. Int J Geriatr Psychiatry 2011;26:307-313.

100. Robinson M, Kendall GE, Jacoby P et al. (2011) Lifestyle and demographic correlates of poor mental health in early adolescence. J Paediatr Child Health 47, 5461.

101. Salamone JD, Correa M, Mingote S, Weber SM. Nucleus accumbens dopamine and the regulation of effort in foodseeking behavior: implications for studies of natural motivation, psychiatry, and drug abuse. J Pharmacol Exp Ther 2003; 305/1: 1-8.

102. Samieri, C., Jutand, M.A., Feart, C., Capuron, L., Letenneur, L., BarbergerGateau, P., 2008. Dietary patterns derived by hybrid clustering method in older people: association with cognition, mood, and selfrated health. J. Am. Diet. Assoc. 108 (9), 1461-1471.

103. Sanchez-Villegas A, DelgadoRodriguez M, Alonso A, Schlatter J, Lahortiga F, et al. (2009) Association of the Mediterranean dietary pattern with the incidence
104.

Sanhueza C, Ryan L, Foxcroft DR. Diet and the risk of unipolar depression in adults: systematic review of cohort studies. J Hum Nutr Diet 2012;26:56-70.

105. Shabbir F, Patel A, Mattison C, Bose S, Krishnamohan R, Sweeney E, Sandhu S, Nel W, Rais A, Sandhu R, et al. Effect of diet on serotonergic neurotransmission in depression. Neurochem Int 2013;62:324329.

106. Silberg JL, Bulik CM. The developmental association between eating disorders symptoms and symptoms of depression and anxiety in juvenile twin girls.

J Child Psychol Psychiatry.2005;1:13171326.

doi:

10.1111/j.14697610.2005.01427.x.

107. Skarupski KA, Tangney C, Li H, Ouyang B, Evans DA, Morris MC. Longitudinal association of vitamin B- 6, folate, and vitamin B-12 with depressive symptoms among older adults over time. Am J Clin Nutr 2010;92:330-335.

108. Slater B, Enes CC, Lopez RV et al. (2010) Validation of a food frequency questionnaire to assess the consumption of carotenoids, fruits and vegetables among adolescents: the method of triads. Cad Saude Publica 26, 2090-2100.

109. Sonneville KR, Horton NJ, Micali N, Crosby RD, Swanson SA, Solmi F, Field AE. Longitudinal associations between binge eating and overeating and adverse outcomes among adolescents and young adults. JAMA Pediatrics. 2013;1:149-155. doi: 10.1001/2013.jamapediatrics.

110. Sonneville KR, Horton NJ, Micali N, Crosby RD, Swanson SA, Solmi F, Field AE. Longitudinal associations between binge eating and overeating and adverse outcomes among adolescents and young adults. JAMA Pediatrics. 2013;1:149-155. doi: 10.1001/2013.jamapediatrics.

111. Sontag LM, Graber JA, BrooksGunn J, Warren MP: Coping with social 
stress: implications for psychopathology in young adolescent girls. J Abnorm Child Psychol 2008; 36: 1159-74.

112. Steinhausen HC, Gavez S, Metzke CW. Psychosocial correlates, outcome, and stability of abnormal adolescent eating behavior in community samples of young people. Int J Eat Disord. 2005;1:119-126. doi: 10.1002/eat.20077.

113. Stice E, Marti C, Shaw HE, Jaconis M. An 8-year longitudinal study of the natural history of threshold, subthreshold, and partial eating disorders from a community sample of adolescents. J Abnorm Psychol. 2009;1:587-597.

114. Su KP. Biological mechanism of antidepressant effect of omega-3 fatty acids: how does fish oil act as a 'mind-body interface'? Neurosignals 2009;17:144-152.

115. Sublette, M.E., Hibbeln, J.R., Galfalvy, H., Oquendo, M.A., Mann, J.J., 2006. Omega-3 polyunsaturated essential fatty acid status as a predictor of future suicide risk. Am. J.

116. Swanson SA, Crow SJ, Le Grange D, Swendsen J, Merikangas KR. Prevalence and correlates of eating disorders in adolescents: Results from the national comorbidity survey replication adolescent supplement. ArchGen Psychiatry. 2011;1(7):714-723.

doi:10.1001/archgenpsychiatry.2011.22.

117. Tanskanen, A., Hibbeln, J.R., Tuomilehto, J., et al., 2001. Fish consumption and depressive symptoms in the general population in Finland. Psychiatr. Serv. 52 (4), 529-531.

118. Tur JA, Bibiloni MM, Sureda A, Pons A. Dietary sources of omega 3 fatty acids: public health risks and benefits. $\mathrm{Br} \mathbf{J}$ Nutr 2012;107 Suppl 2:S23-52.

119. van Egmond-Fro“hlich A, Claussnitzer G, Dammann D, Eckstein E, Bra“uer W, et al. (2012) Parent reported inattention and hyperactivity/impulsivity as predictor of long-term weight loss after inpatient treatment in obese adolescents. Int J Eat Disord. doi: 10.1002/eat.22043.

120. Wang Z, Zhai F, Du S et al. (2008) Dynamic shifts in Chinese eating behaviors. Asia Pac J Clin Nutr 17, 123-130.

121. Wentz E, Gillberg IC, Anckarsäter H, Gillberg C, Rastam M: Adolescentonset anorexia nervosa: 18-year outcome. $\mathrm{Br} \mathrm{J}$ Psychiatry 2009; 194:168-74

122. Wittchen HU, Müller N, Pfister H, Winter S, Schmidtkunz B: Affektive, somatoforme und Angststörungen in Deutschland. Erste Ergebnisse des bundesweiten Zusatzsurveys „Psychische Störungen". Gesundheitswesen 1999; 61: 216-22.

123. women. Am J Psychiatry 167: $305-$ 311.

124. World Health Organization, 2005. Atlas: Child and Adolescent Mental Health Resources. World Health Organization, Geneva.

125. Zhang X, Dong F, Ren J, Driscoll MJ, Culver B (2005) High dietary fat induces NADPH oxidase-associated oxidative stress and inflammation in rat cerebral cortex. Exp Neurol 191: 318-325. 